\title{
PbS Thin Films for Photovoltaic Applications Obtained by Non-Traditional Chemical Bath Deposition
}

\author{
PÉREZ-GARCÍA Claudia Elena ${ }^{1, a}$, RAMÍREZ-BON Rafael ${ }^{1, b}$ and \\ VOROBIEV Yuri, ${ }^{1, c}$ \\ ${ }^{1}$ Cinvestav del IPN, Unidad Querétaro, Libramiento Norponiente 2000, Juriquilla, 76230, México
}

\begin{abstract}
To optimize cost-efficiency relation for thin film solar cells, we explore the recently developed versions of chemical deposition of semiconductor films, together with classic CBD (Chemical Bath Deposition): SILAR (Successive Ionic Layer Adsorption and Reaction) and PCBD (Photo Chemical Bath Deposition), all of them ammonia-free and ecologically friendly. The films of $\mathrm{CdS}$ and $\mathrm{PbS}$ were made, and experimental solar cells with $\mathrm{CdS}$ window layer and $\mathrm{PbS}$ absorber elaborated. We found that band gap of $\mathrm{PbS}$ films can be monitored by deposition process due to porosity-induced quantum confinement which depends on the parameters of the process. We expect that the techniques employed can be successfully used for production of optoelectronic devices.
\end{abstract}

\section{Introduction}

The most important problem in development of modern solar cells is the production cost which includes the cost of materials and that of technologies involved as well as the energy consumption at technological processes. Besides, the corresponding technology of production of devices for generation of clean energy should be ecologically clean.

One of the techniques that is traditionally used to prepare thin films of chalcogenide semiconductors for solar cells and photo detectors, like $\mathrm{CdS}$ and $\mathrm{PbS}$, is the Chemical Bath Deposition (CBD) [1-3] that is simple, cheap and energy efficient. Chemically deposited CdS window layers have been used in the last years in high efficiency $\mathrm{CdTe} / \mathrm{CdS}$ solar cells. However, the generally accepted CBD recipes usually utilizes ammonia which is highly volatile, toxic and thus harmful to the environment. Furthermore, the volatility of ammonia changes conditions of reaction solution during the deposition process resulting in irreproducible film properties.

Recently in our group an alternative, ammonia-free CBD process was developed for the growth of high quality chalcogenide thin films [3-5]. In particular, using only ammonia-free CBD processes we produced $\mathrm{CdS} / \mathrm{PbS}$ solar cell with energetic efficiency of $1.6 \%$ and quantum efficiency of $25 \%$ [6]. It should be mentioned that $\mathrm{PbS}$ as absorber in solar cell is very promising material, being very sensitive to crystallite size so that its band gap can be monitored to great extent. Here we present the results of investigation of $\mathrm{CdS}$ and $\mathrm{PbS}$ thin films produced by traditional $\mathrm{CBD}$ and its variations like SILAR (Successive Ionic Layer Adsorption and Reaction) and PCBD (Photo Chemical Bath Deposition), including some preliminary results of studying of solar cells based on these materials.

\section{Experimental methods}

Technique of deposition of CdS thin film was not different from that described in [6]. To obtain $\mathrm{PbS}$ film by traditional ammonia-free CBD, the substrate (either Corning glass microscope slide or $\mathrm{Si}$ wafer) was immersed vertically in a solution of $100 \mathrm{ml}$ containing: $5 \mathrm{ml}$ of $0.5 \mathrm{M}$ lead acetate $\mathrm{Pb}\left(\mathrm{C}_{2} \mathrm{H}_{3} \mathrm{O}_{2}\right)_{2}$ as source of $\mathrm{Pb}+$ ions; $5 \mathrm{ml}$ of $2 \mathrm{M}$ sodium hydroxide $(\mathrm{NaOH}) ; 6 \mathrm{ml}$ $1 \mathrm{M}$ of thiourea $\mathrm{CS}(\mathrm{NH} 2)_{2}$ to produce $\mathrm{S}$ - ions; $2 \mathrm{ml} 1 \mathrm{M}$ of Triethanolamine (TEA $\mathrm{C}_{6} \mathrm{H}_{15} \mathrm{NO}_{3}$ ) as complexing agent and water, the process was performed at room temperature. To realize the Photo Chemical Bath Deposition, the same solution was used, but illumination with UV light was added. The possibility of using PCBD for production of chalcogenide films was demonstrated earlier [7].

For SILAR deposition we used 0.5M lead of acetate solution complexed with $0.1 \mathrm{M}$ of TEA as a cationic precursor and $0.2 \mathrm{M}$ of Thioacetamide $\mathrm{C}_{2} \mathrm{H}_{5} \mathrm{NS}$ as an anionic precursor. The optimized absorption and reaction time for cationic solution was $60 \mathrm{~s}$ and for the anionic one $30 \mathrm{~s}$. A Corning glass substrate was immersed in cationic precursor solutions, and after $60 \mathrm{~s}$ the unabsorbed ions were removed by rinsing substrate in distillated water, then the substrate was immersed in anionic precursor solution, after that, the substrate was

acperez@qro.cinvestav.mx, ${ }^{\mathrm{b}}$ rbbon@qro.cinvestav.mx, ${ }^{\mathrm{c}}$ vorobiev@qro.cinvestav.mx 
dried during $60 \mathrm{~s}$, and finally the substrate was rinsed in distilled water to remove unabsorbed ions. The cycle was repeated up to 50 times.

The films were characterized using X-ray diffractometry, Scanning Electron Microscopy (structure and morphology); optical transmittance and reflection were studied with spectrophotometer FilmTek TM-3000. The energy band gap values for PbS films were calculated from transmittance spectra obtained with Si substrates using FTIR spectrometer Perkin-Elmer GX, in the range $200-7800 \mathrm{~nm}$; en error in the band gap value found we estimate as $5 \%$.

To construct a solar cell, the CdS window layer was deposited onto the Corning glass slide covered with conductive ITO layer, then PbS film over the $\mathrm{CdS}$ was produced, and finally the graphite contact was placed above the $\mathrm{PbS}$ film; the cell was illuminated through the glass slide. The cell's parameters were found with Semiconductor Parameters Analyzer Agilent 4155C, with an accuracy of $3 \%$.

\section{Results and discussion}

Fig. 1 presents the X-ray diffractograms of $\mathrm{PbS}$ films made by CBD, SILAR y PCBD; all patterns are practically the same showing that material obtained was cubic $\mathrm{PbS}$ (galena) in all cases.

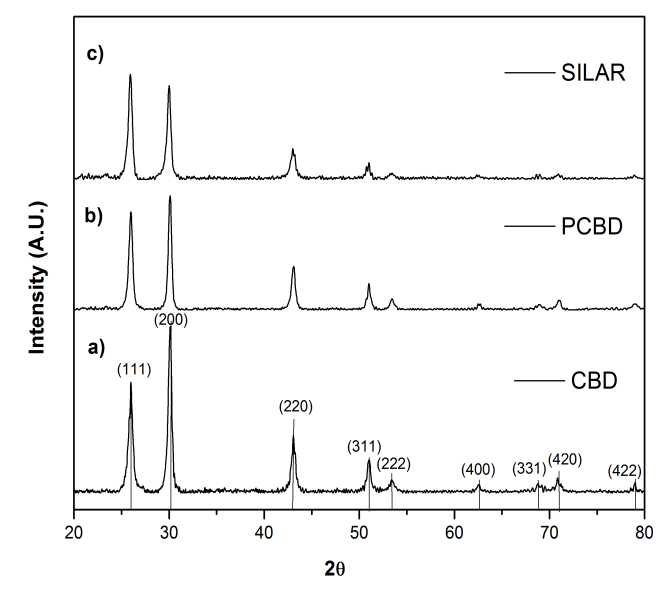

Figure 1. X-ray diffraction patterns of $\mathrm{PbS}$ films prepared by three types of chemical deposition

Fig. 2 shows the dependence on time of thickness for CBD and PCBD made PbS films. It is seen that the UV illumination greatly enhances the deposition rate: during $5 \mathrm{hrs}(300 \mathrm{~min})$ the CBD film has thickness of around $200 \mathrm{~nm}$, whereas in PCBD case thickness after 5 hrs is $750 \mathrm{~nm}$. Still longer deposition time in PCBD case does not increase thickness because the solution was exhausted. The mechanism of action of UV illumination will be discussed in another publication; here we only mention that the energy of photons employed is larger than binding energy of essential components of the reaction, thus illumination helps in liberating of ions - participants in film's formation.
In case of SILAR, not the time is significant, but number of cycles. During 40 cycles, the thickness of $2000 \mathrm{~nm}$ was reached.

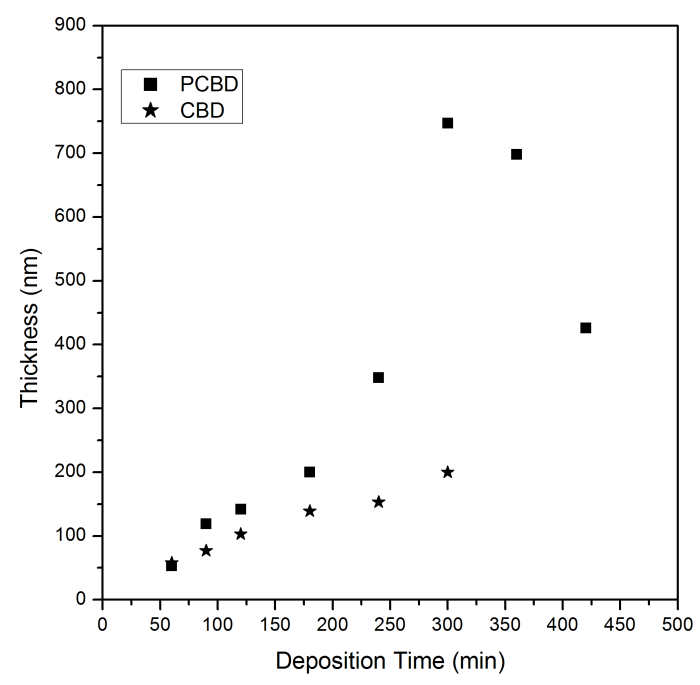

Figure 2. Dependence of film thickness upon deposition time (stars for CBD, squares for PCBD.

From optical spectra of the films obtained, the band gap values Eg were calculated. They are shown in Fig. 3 for PCBD films (left) and SILAR ones (right)).
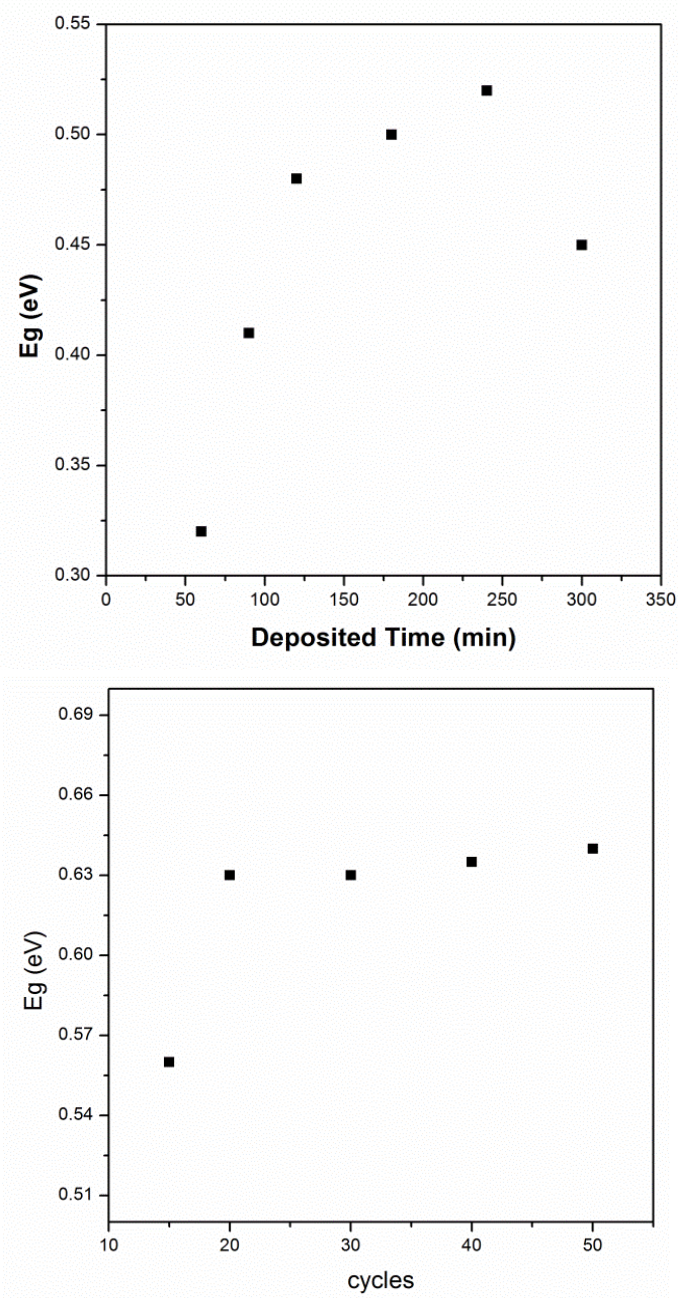
Figure 3. Variation of band gap during deposition process in PCBD (left) and SILAR films (right).

In both cases, an average value of $\mathrm{Eg}$ exceeds the value for bulk material, and increases with the time (number of cycles) of the process. It shows the quantum confinement effect induced by material porosity (see [8] for details) and indicates that porosity increases with the time of deposition. In SILAR-made films, the porosity is greater than in PCBD films; correspondingly, the solar cell made of SILAR films had parameters inferior to those for PCBD film. A device scheme and currentvoltage characteristics for cell with PCBD PbS films are presented in Fig. 4. It could be seen that the cell parameters have non-monotonous dependence on time of deposition: the film deposited for $3 \mathrm{hrs}$ gives better characteristic than film of 2 and $4 \mathrm{hrs}$. In the best case, efficiency was $0.22 \%$, and fill factor FF 0.53 . These are preliminary data, to be investigated later.

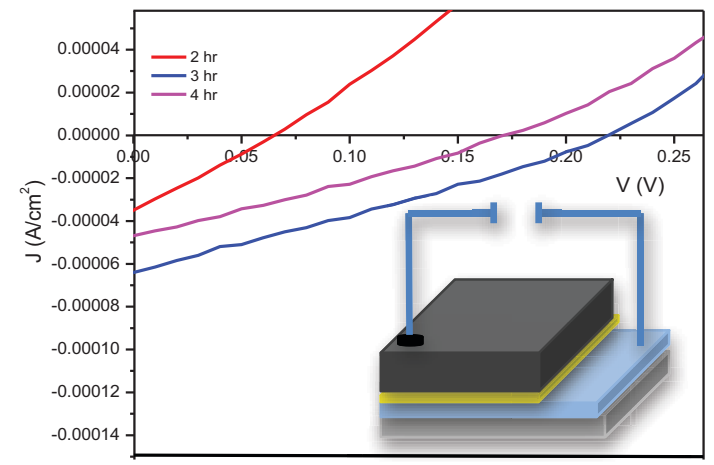

Figure 4. A scheme of solar cell, with layers from the bottom: glass, ITO, CdS, PbS made by PCBD, graphite contact. The graph shows I-V curves for cells with different time of production of $\mathrm{PbS}$ film.

\section{Summary}

We demonstrated that recent versions of CBD process PCBD and SILAR - are cheap and efficient, and can produce materials adequate for important photovoltaic devices.

\section{References}

1. T. Nakada, M. Mitzutani, Y. Hagiwara, A. Kunioka, High-efficiency $\mathrm{Cu}(\mathrm{In}, \mathrm{Ga}) \mathrm{Se}_{2}$ thin film solar cells with a CBD-ZnS buffer layer, Sol. Energy Mater. Sol. Cells 67 (2001) 255-260.

2. C.D. Lokhande, E.H. Lee, K.D. Jung, Q.S. Joo, Ammonia-free chemical bayh method for deposition of microcrystalline cadmium selenide films, Mater. Chem. Phys. 91 (2005) 200-204.

3. M.B. Ortuño-López, J.J. Valenzula-Jauregui, M. Sotelo-Lerma, A. Mendoza-Galvan, R. Ramírez-
Bon, Highly oriented CdS films deposited by an ammonia-free chemical bath method, Thin Solid Films 429 (2003) 34-39.

4. J.J. Valenzula-Jauregui, R. Ramírez-Bon, A. Mendoza-Galvan and M. Sotelo-Lerma, Optical properties of $\mathrm{PbS}$ thin films chemically deposited at different temperatures. Thin Solid Films 441 (2003), 104-110.

5. R. Ochoa-Landín, J. Sastre-Hernández, O. VigilGalán and R. Ramírez-Bon, Chemically deposited CdS by an ammonia-free process for solar cells window layers. Solar Energy 84 (2010) 208-214.

6. J. Hernandez Borja, Y.V. Vorobiev, R. Ramirez Bon, Thin film solar cells of $\mathrm{CdS} / \mathrm{PbS}$ chemically deposited by an ammonia-free process, Sol. En. Mat. Solar Cells, 95 (2011) 1882-1888.

7. F. Goto, M. Ichimura, E. Arai, A new technique of compound semiconductor deposition from an aqueous solution by photochemical reactions, Japanese J. Appl. Physics, 36 (1997)1143-1146.

8. Y. V Vorobiev, P.P. Horley, J. Hernández-Borja, H.E. Esparza-Ponce, R. Ramírez-Bon, P. Vorobiev, et al., The effects of porosity on optical properties of semiconductor chalcogenide films obtained by the chemical bath deposition, Nanoscale Res. Lett. 7 (2012) 483-488. 